\title{
Feasibility of Low-Cost Particle Sensor Types in Long-Term Indoor Air Pollution Health Studies After Repeated Calibration Over a 2-Year Timeframe
}

\section{Elle Anastasiou}

New York University Grossman School of Medicine, Department of Population Health

\section{J. Ruzmyn Vilcassim}

University of Alabama, Department of Environmental Health Sciences, UAB School of Public Health

John Adragna

New York University Grossman School of Medicine, Department of Environmental Science

Emily Gill

New York University Grossman School of Medicine, Department of Population Health

\section{Albert Tovar}

New York University Grossman School of Medicine, Department of Population Health

\section{Lorna E. Thorpe}

New York University Grossman School of Medicine, Department of Population Health

Terry Gordon ( $\nabla$ terry.gordon@nyulangone.org)

New York University Grossman School of Medicine, Department of Environmental Science

\section{Research Article}

Keywords: calibration, low-cost particle sensor, air monitoring, air pollution, secondhand smoke

Posted Date: October 29th, 2021

DOI: https://doi.org/10.21203/rs.3.rs-996536/v1

License: (c) (1) This work is licensed under a Creative Commons Attribution 4.0 International License. Read Full License 


\section{Abstract \\ Background}

Previous studies have explored using calibrated low-cost particulate matter (PM) sensors, but important research gaps remain regarding long-term performance and reliability.

\section{Objective}

Evaluate longitudinal performance of low-cost particle sensors by measuring sensor performance changes over 2 years of use.

\section{Methods}

51 low-cost particle sensors (Airbeam $1 \mathrm{~N}=29$; Airbeam $2 \mathrm{~N}=22$ ) were calibrated four times over a 2-year timeframe between 20192021. Cigarette smoke-specific calibration curves for Airbeam 1 and 2 PM sensors were created by directly comparing simultaneous 1-min readings of a Thermo Scientific Personal DataRAM PDR-1500 unit with a $2.5 \mu \mathrm{m}$ inlet.

\section{Results}

Inter-sensor variability in calibration coefficient was high, particularly in Airbeam 1 sensors at study initiation. Calibration coefficients for both sensor types trended downwards over time to $<1$ at final calibration timepoint [Airbeam $1 \mathrm{Mean}(\mathrm{SD})=0.87$ (0.20); Airbeam 2 Mean (SD) = $0.96(0.27)$ ]. We lost more Airbeam 1 sensors $(\mathrm{N}=27$, failure rate $48.2 \%)$ than Airbeam $2(\mathrm{~N}=2$, failure rate $16.7 \%$ ) due to electronics, battery, or data output issues.

\section{Conclusions}

Evidence suggests degradation over time might depend more on particle sensor type, rather than individual usage. Repeated calibrations of low-cost particle sensors may increase confidence in reported PM levels in longitudinal indoor air pollution studies.

\subsection{Introduction}

Studies of air pollution-associated health impacts often require measuring ambient concentrations of air pollutants. While monitoring of $\mathrm{PM}_{2.5}$ concentrations has contributed to understanding and reducing ambient $\mathrm{PM}_{2.5}$ to improve air quality standards, rigorous measurement of indoor air pollution remains a challenge.

Conventionally, the measurement of ambient $\mathrm{PM}_{2.5}$ concentrations requires either a labor-intensive gravimetric filter-based method with size-specific inlets, or sophisticated and approved real-time instruments. Such equipment is expensive and not readily portable, thus limiting the number of locations that can be sampled within a given time. Central monitoring networks that use advanced instruments utilizing gravimetry, light scattering, or beta attenuation have been mounted by states and federal agencies to address efforts to achieve federal national ambient air quality standards (NAAQS). While central monitoring is obviously important for monitoring $\mathrm{PM}_{2.5}$ exposures within the microenvironments of cities, neighborhoods, buildings, and even homes, personal monitoring is considered the optimal approach to assess an individual's exposure levels to $\mathrm{PM}_{2.5}{ }^{1}$

Until recently, monitoring indoor settings at a high spatial and temporal resolution was impractical due to the cost, size, and expertise needed to operate monitoring equipment. Real-time personal monitoring or multi-location monitoring is, however, not a new concept. Innovations in air quality monitoring have addressed cost in the last decade. A combination of technological advancements (cheaper electronic boards and smaller light scattering sensors), public interest in air pollution, and the increased popularity of citizen science have resulted in the development and proliferation of low-cost $\mathrm{PM}_{2.5}$ sensors and devices. These low- 
cost sensors have gained in popularity for a range of uses from home and personal monitoring to citizen science and to larger scale academic research. ${ }^{2-4}$

The advantages of low-cost $\mathrm{PM}_{2.5}$ sensors for research include: 1) deployment in large numbers to increase spatial and temporal coverage; 2) ease of use and maintenance; and 3) a battery power source that permits remote or portable use. ${ }^{5-7}$ In addition, they can be connected via Wi-Fi or Bluetooth technology to transmit data, sometimes in real time, to central servers and crowdsourcing platforms to share data and cover large geographic areas with extended spatial and temporal resolution. However, these simple, low-cost sensors have limitations and require routine testing and calibration prior to use in scientific studies. Much work has been done in recent years to address these limitations, and results have demonstrated that low-cost sensors generally have acceptable reliability but also technological limitations and inter-instrument variability. ${ }^{2,7} \mathrm{~A}$ key finding of many of these studies is that important research gaps remain regarding durability and the need for calibration of individual units prior to use for research. 5,7-9

Few studies, for example, have examined the performance of a network of low-cost sensors over an extended period of time. One such study showed that some $\mathrm{PM}_{2.5}$ sensors were relatively stable over time when tested over a year, however that study focused on measurements in outdoor environments with concentrations ranging from $6-41 \mu \mathrm{g} / \mathrm{m}^{3}{ }^{10}$ In tandem, public housing authorities (PHAs) have been federally mandated to implement smoke-free housing (SFH) policies in their developments. ${ }^{11-13}$ Despite policy implementation in July 2018, there is still some evidence of cigarette smoking within New York City Housing Authority (NYCHA) developments. ${ }^{11}$ Stemming from a larger, quasi-experimental study evaluating the impact of SFH policies on secondhand smoke exposure in select NYCHA buildings, we utilized a network of low-cost sensors to evaluate indoor PM. This current analysis sought to assess whether rigorous calibration allows low-cost sensors to be used for indoor air quality measurements in the field for long periods of time without degradation in reliability. To achieve this objective, we repeatedly calibrated and utilized a large number of low-cost first and second generation Airbeam $\mathrm{PM}_{2.5}$ sensors, over a 2-year period, to assess $\mathrm{PM}_{2.5}$ concentrations in urban high-rise buildings with a focus on measuring indoor tobacco smoke.

\subsection{Methods}

\subsubsection{Generation of Calibration Curves for Cigarette Smoke:}

Cigarette smoke-specific calibration curves for the Airbeam 1 and $2 \mathrm{PM}_{2.5}$ sensors were created in a laboratory setting via the direct comparison of the output of the low cost Airbeam sensors with simultaneous 1-min readings produced by a factory-calibrated Thermo Scientific Personal DataRAM PDR-1500 unit with a $2.5 \mu \mathrm{m}$ inlet (Thermo Environmental Instruments, Waltham, MA). The PDR-1500 unit is a widely used instrument and shown to be reliable from previous studies. ${ }^{14-22}$ Over the course of the 2-year period, our low-cost sensors were calibrated four times using the same PDR-1500 unit, where the internal filter was checked to control the real-time measurements gravimetrically. The Airbeam 1 and 2 devices utilize two low-cost sensors: The Shinyei PPD60PV and Plantower PMS 7003 infra-red light scattering particle sensors, respectively. The PDR 1500 unit was zeroed with particle-free air prior to each run.

To perform the calibration, 8-12 Airbeam units were placed into an airtight stainless-steel chamber, where temperature is room temperature and humidity matches the building's at below $50 \%$, with access ports permitting the introduction of cigarette smoke or HEPA filtered air. The PDR-1500 was connected to a sampling port for measuring the $\mathrm{PM}_{2.5}$ concentrations inside the chamber. This instrument has both an inlet and outlet where tubes are connected to inject cigarette smoke into the chamber; the PDR-1500 was not placed inside the chamber to prevent contamination resulting from its enclosure with cigarette smoke. A smoking machine (Borgwaldt, Hamburg, Germany) was used to inject fresh mainstream cigarette smoke using 3R4F reference cigarettes into the chamber until the PDR-1500 registered a particle mass concentration greater than $1,000 \mu \mathrm{g} / \mathrm{m}^{3}$. A high concentration value such as $1,000 \mu \mathrm{g} / \mathrm{m}^{3}$ exceeds the upper limit for $\mathrm{PM}_{2.5}$ values for both low-cost particle sensor types. Airbeam 1 and Airbeam 2 sensors have different saturation points at $80 \mu \mathrm{g} / \mathrm{m}^{3}$ and $200 \mu \mathrm{g} / \mathrm{m}^{3}$, respectively (i.e., the light scattering derived $\mathrm{PM}_{2.5}$ output plateaus), ensuring the decreasing $\mathrm{PM}_{2.5}$ calibration curve would begin above their detection ceiling (approximately $180 \mu \mathrm{g} / \mathrm{m}^{3}$ and 800 $\mu \mathrm{g} / \mathrm{m}^{3}$, respectively). After cigarette smoke generation was stopped, the sample pump and internal filter of the PDR-1500 slowly removed cigarette smoke from the chamber which was replaced by HEPA-filtered room air. The resulting time-dependent decrease 
in $\mathrm{PM}_{2.5}$ was used to develop the calibration curve. The start times of the Airbeam units and PDR-1500 particulate matter readings were synchronized, and the 1 min outputs were recorded beginning above the nominal upper detection limit and continued until the PDR-1500 values stabilized in the low single digit $\mu \mathrm{g} / \mathrm{m}^{3}$ range. Each run lasted approximately one hour.

Readings from each Airbeam (X-axis) were matched by synchronized timestamp with the corresponding values from the PDR-1500 (Y-axis). Using Excel, a unique calibration equation for each Airbeam unit was calculated by linear regression up to $80 \mu \mathrm{g} / \mathrm{m}^{3} \mathrm{which}$ was the expected upper limit for indoor $\mathrm{PM}_{2.5}$. Polynomial regression models were also generated; however, the output of these models was linear up to $80 \mu \mathrm{g} / \mathrm{m}^{3}$, which strengthened our decision to use linear models. Each unique equation and accompanying $R$ value was recorded and assigned to the unit by serial number. Because of differences in the sensor type's output, for consistency, we calculated calibration coefficients using the total PM reading from Airbeam 1 sensors, and the PM 10 output from Airbeam 2 sensors. Both sensor types use an algorithm based on an internal equation to generate PM output; Airbeam 1 sensors do not have the split for $\mathrm{PM}_{1}, \mathrm{PM}_{2.5}$ and $\mathrm{PM}_{10}$ values. The calibration coefficient for cigarette smoke was developed as a multiplication factor to correct the Airbeam $\mathrm{PM}_{2.5}$ output and calculated as:

Calibration Coefficient $=$ slope of the PDR-1500 (Y-axis) vs Airbeam (X-axis) calibration curve

To assess the effect of particle composition on the calibration curve, the Airbeam devices were also calibrated using airborne particles in the NYC subway system. As in the cigarette smoke calibration procedure, the output of four Airbeam 1's and four Airbeam 2's was compared to the PDR 1500 PM $_{2.5}$ output and a calibration coefficient was calculated for subway $\mathrm{PM}_{2.5}$.

\subsubsection{Field Sampling Periods}

We calibrated 51 low-cost particle sensors (Airbeam 1 generation N=29; Airbeam 2 generation N=22) at 4 different timepoints over a 2-year period spanning from 2019 to 2021 . After each laboratory calibration, the Airbeam units were deployed in a large, natural experiment evaluating the impact of new smoke-free housing (SFH) policies on air quality in public housing units every 6 months. ${ }^{11,23}$ Due to the onset of the COVID-19 pandemic, we were unable to perform Airbeam sensor calibration 24 months postSFH policy implementation (April-September 2020). A calibration technical error for select Airbeam 2 sensors occurred at 30 months post-SFH policy (December-March 2021), leading to their exclusion from data analysis at that timepoint. We then calibrated all 51 Airbeam sensors at 36 months post-SFH policy (May-September 2021) to obtain a final calibration coefficient.

\subsubsection{Data Analysis:}

We descriptively tabulated the mean (SD) calibration coefficients at four different 6-month timepoints over a 2-year period from 2019 to 2021 for the two different Airbeam sensor types. We performed independent t-tests to measure statistically significant differences in calibration coefficient means between particle sensor types, and also characterized the between-and-within variability for calibration coefficient measurements. Because the light scattering properties of airborne particles are influenced by particle composition, we compared the mean (SD) calibration coefficients for cigarette smoke and subway $\mathrm{PM}_{2.5}$ using an independent ttest. Lastly, we used a difference-in-difference (DID) approach to compare within-group changes between Airbeam 1 and Airbeam 2 sensors across four different calibration timepoints. Regression models included fixed effects for particle sensor type (Airbeam 1 vs Airbeam 2 sensors) and data collection timepoints (12, 18, 30 and 36 months post-SFH policy implementation ${ }^{24}$ ). We adjusted for the clustering of individual Airbeam IDs and repeated measures overtime. Model-based mean differences with $95 \%$ confidence intervals were calculated for each particle sensor type over time. P-values were reported after implementation of the independent ttests, with a significance level set at $p<0.05$, using a two-sided test. All analyses were performed using SAS statistical software, version 9.4 (SAS institute).

We examined the individual time trends in calibration coefficient measurements for low-cost particle sensors over a 2-year period, grouped by particle sensor type (Supplemental Figure S1), and descriptively categorized all low-cost particle sensors that were taken out of circulation over the 2-year period (Supplemental Table S1). We then examined the correlation between the number of unique instances of use for individual Airbeam sensors, and their final calibration coefficients at the end of the 2-year period (Supplemental Table S2 and Supplemental Figure S2). 


\subsection{Results}

\subsubsection{Sample Characteristics}

We conducted a descriptive characterization of the mean (SD) calibration coefficients at four different timepoints over a 2-year timeframe from 2019 to 2021 (Figure 1). At our first timepoint, our sample included a total of N=56 Airbeam 1 sensors and N=24 Airbeam 2 sensors. We observed more equipment failure over time in Airbeam 1 sensors ( $n=27$, failure rate 48.2\%) than in Airbeam 2 sensors ( $n=2$, failure rate $16.7 \%$ ). These equipment failures occurred for a variety of reasons including, but not limited to: cockroach infestations, not recording data properly (i.e., inconsistent relative humidity, temperature, or PM outputs), reading null values in PM measurements, and failure during calibration (Supplemental Table S1). As a result, our effective sample size decreased to $\mathrm{N}=37$ Airbeam 1 sensors and $\mathrm{N}=21$ Airbeam 2 sensors at the second timepoint, and $\mathrm{N}=29$ Airbeam 1 sensors and $\mathrm{N}=22$ Airbeam 2 sensors at the third and fourth timepoints. We thus restricted these analyses to the $\mathrm{N}=29$ Airbeam 1 sensors and $\mathrm{N}=22$ Airbeam 2 sensors available across all 4 calibration time points. The $\mathrm{PM}_{2.5}$ concentration readout of Airbeam $\mathrm{PM}_{2.5}$ sensors was less than that of the PDR-1500 reference instrument at each calibration timepoint.

\subsubsection{Between-and-Within Variability in Calibration Coefficients for low-cost particle sensor types}

On an individual unit basis, we observed a high degree of inter-sensor variability in calibration coefficients across both low-cost particle sensors types over a 2-year timeframe (Figure 1). There was a notable decline in Airbeam calibration coefficients consistent across both low-cost particle sensor types, with greater inter-monitor variability observed in Airbeam 1 sensors at the first calibration timepoint and in Airbeam 2 sensors at the fourth calibration timepoint. During the second calibration timepoint, the mean (SD) calibration coefficient for Airbeam 1 sensors (1.14 (0.22)) was lower compared to Airbeam 2 sensors (1.59 (0.25)) $(p<0.0001)$. Because of the technical errors in the Airbeam 2 calibrations, a calibration coefficient mean was determined only for Airbeam 1 sensors $(1.19(0.34))$ during the third calibration timepoint. Overall, Airbeam 2 sensors fared better over the 2-year timeframe compared to Airbeam 1 sensors.

\subsubsection{Least Square Mean Differences in Calibration Coefficients for low-cost particle sensor types}

We conducted a DID model approach for repeated measures, and characterized the least square mean differences [(MD $(95 \% \mathrm{Cl})]$ spanning from 2019 to 2021, for each low-cost particle sensor type (Table 1). Among Airbeam 1 sensors, the degree of intermonitor change over time was statistically significant across all four time points, with the exception of change between the second and third timepoints $[(-0.05(-0.23,0.14)](p=0.6)$. Among Airbeam 2 sensors, the degree of inter-monitor change over time was only statistically significant between the second and fourth timepoints $[(0.62(0.46,0.78)]$ and between the first and fourth timepoints $[(-0.60(-0.76,-0.44)]$, but not statistically significant between the first and second timepoints $[(0.02(-0.14,0.18)](p=0.8)$. We calculated the inter-monitor change over time among three timepoints only (12, 18 and 36 months post-SFH policy) for Airbeam 2 sensors due to a calibration malfunction at 30 months post-SFH policy implementation.

\subsubsection{Comparison of Calibration Coefficients for Cigarette Smoke versus Subway Particulate Matter}

Because particle composition can affect light scattering properties, we characterized the calibration coefficients for two different particle types at a single timepoint (Table 2) and compared the calibration coefficients for cigarette smoke vs. particulate matter $\left(\mathrm{PM}_{2.5}\right)$ present in subway stations. The calibration coefficients of $1.79(0.76)$ for cigarette smoke and $1.22(0.39)$ for subway $\mathrm{PM}_{2.5}$ were not statistically different $(p=0.08)$.

\subsubsection{Correlation between Unique Instances of Use and Final Calibration Coefficient for Individual low-cost particle sensor types}

To determine if sensor usage affected Airbeam output over time, we characterized the unique instances of use (i.e., the number of 7-day indoor sampling periods that a sensor was used), and the final calibration coefficient for all 51 individual Airbeam sensors (Supplemental Table S2). We examined the correlation between the number of 7-day indoor sampling periods that an individual sensor was used, and its final calibration coefficient at the fourth calibration timepoint (Supplemental Figure S2). We did not observe a strong correlation for Airbeam 1 sensors $\left(R^{2}=0.16\right)$ or for Airbeam 2 sensors $\left(R^{2}=0.09\right)$. The slope of the curve for Airbeam 1 suggests that the more the sensors were used, the greater the deviation of its output from the PDR-1500's output, while the Airbeam 2 curve suggested no change with an increase in usage. 


\subsection{Discussion}

To our knowledge, this analysis is one of the first long-term longitudinal assessments of performance and reliability of low-cost particle sensors in measuring indoor tobacco smoking. We observed a high degree of inter-sensor variability across both particle sensor types, particularly in Airbeam 1 sensors at the study's initiation. Change in calibration coefficients over time for individual Airbeam units was detected, suggesting a degradation of low-cost particle sensors for longitudinal assessment (Supplemental Figure S1). There were also notable downward trends in calibration coefficients over time, whereas the accompanying $\mathrm{R}$ value for both Airbeam 1 and 2 sensors was below 1 at the final calibration timepoint. Findings lend support to the conclusion that the routine calibration of individual Airbeam units might help to improve their utility and performance over time. Overall, Airbeam 2 particle sensors fared better than Airbeam 1 sensors, suggesting greater durability of Airbeam 2 sensors for longitudinal assessment.

Our findings suggest that low-cost particle sensors might be differentially subjected to degradation, seen in the greater loss of Airbeam 1 sensors than Airbeam 2 sensors over time. While two of these failures, and the loss of units, resulted directly from the public housing environments (i.e., roach infestation), other failures were more generally concerning for the use of non-calibrated low-cost particle sensors for longitudinal assessment of air quality. Interestingly, we did not observe a strong correlation between the unique instances of field use of sensors over the 2-year period and their final calibration coefficients measured at the fourth calibration timepoint, suggesting that low-cost sensor degradation over time might be more contingent on particle sensor type, rather than individual sensor usage.

Surprisingly, the calibration coefficients were not different for cigarette smoke or subway PM (primarily combustion products and iron-rich friction particles, respectively), suggesting that the light scattering physics of these low-cost particle sensors was not significantly affected by these two particular particle types. Our finding of similar calibration coefficients was limited to two particle types; however, and further studies would be needed to assess a range of particles with different compositions. Other researchers have observed that, in addition to particle composition, the accuracy of $\mathrm{PM}_{2.5}$ sensor output also depends upon particle size and humidity. ${ }^{24}$ Thus, low-cost sensors require routine calibration in the laboratory with the $\mathrm{PM}_{2.5}$ and environmental conditions of interest.

Our current analysis provides a robust assessment of the longitudinal utility of low-cost particle sensors. Previous studies have measured the utility of low-cost particle sensors for PM monitoring where reference-standard equipment is not available or feasible, and for improving the study of spatially localized airborne PM concentrations. One study conducted in the United Kingdom evaluated the performance of four models of low-cost PM sensors, and examined inter-model performance across 19 different particle sensor units. Despite differences in the way each sensor type derived PM concentrations, the researchers found general agreement in PM readings across sensor types. ${ }^{25}$ Another study evaluated the performance of two widely-used particle sensors, the Plantower PMS A003 and Shinyei PPD42NS, and developed PM calibration models for seven different metropolitan areas (i.e., Los Angeles, Chicago, New York, Baltimore, Minneapolis-St. Paul, Winston-Salem and Seattle) using a sample of 72 sensors. The authors found that good calibration models were feasible only with the Plantower PMS A003 model after running simulations for region-specific models. ${ }^{5}$ Another study found that a Plantower PMS 1003 sensor provided reliable PM data outputs over a 13month period. ${ }^{10}$ Our study extended this time period to over 2 years of reliable output from Plantower PM sensors (albeit a different model), although the reproducibility of the calibration coefficients varied by individual units over time. One of the largest programs of low-cost sensor use is currently underway with the U.S. EPA's AirNow network of low-cost PurpleAir sensors for the nationwide monitoring of wildfire-generated PM (https://www.airnow.gov/fires/using-airnow-during-wildfires/). As demonstrated in our study of Airbeam sensors, the PurpleAir sensors report PM levels that differ from more expensive and reliable monitoring instruments, but these offsets can be corrected by a 'correction equation.' The underlying design of the PurpleAir device is based on the fact that low cost sensors may degrade over time and therefore the PurpleAir device evaluates individual sensor degradation by continually comparing the output of two low-cost Plantower PM sensor units built into each monitoring device. ${ }^{26}$ As such, the EPA has published guidelines on the use and performance testing of low-cost air pollution sensors (https://cfpub.epa.gov/si/si_public_record_Report.cfm?dirEntryld=350785\&Lab=CEMM). Without such corrections, caution is necessary regarding the reliability of low-cost PM sensors over time. 
There were several limitations to our research. Overall, the PM output of each low-cost particle sensor differed from the PM output of the widely used PDR-1500 which has an air flow regulation and infra-red laser that are far more precise than what is available in the low-cost PM sensors, suggesting a potential for under- or over-estimation of PM levels when calibration methods are not utilized. Over time, we experienced equipment failures in a significant number of sensors, particularly the Airbeam 1 generation, thus reducing our effective sample size in this calibration study. There were also a number of strengths to our research. Our study provides a robust assessment of the utility of low-cost particle sensors among a large number of a single brand of two generations of particle sensors available for purchase and utilized in citizen science across the U.S. ${ }^{27}$ We compared the robustness of these two low-cost Airbeam particle sensor types, as well as across two different calibration particle types. We restricted our analysis to sensors that did not provide evidence of malfunction over time, and measured calibration coefficients over a 2-year period, allowing for the assessment of the reliability of these particles for air quality monitoring.

\subsection{Conclusions}

We observed modest changes in calibration coefficient measurements over a 2-year timeframe among both low-cost Airbeam particle sensor types, but in general the later generation Airbeam 2 model was more reliable, suggesting that specific particle sensors may yield better longitudinal consistency. While we did observe a degree of inter-monitor variability, changes in calibration coefficient measurements were relatively consistent across Airbeam 1 and 2 sensors. Finally, we did not observe a significant difference in calibration coefficients when using cigarette smoke and subway PM as the calibration PM. As noted by our results and that of other researchers, low-cost PM sensors can provide reliable and consistent air quality data but regular calibration of the monitors is necessary to optimize their utility.

\section{Abbreviations}

PM

particulate matter

NAAQs

national ambient air quality standards

SFH

smoke-free housing

EPA

Environmental Protection Agency

PHA

Public Housing Authority

\section{Declarations}

The study protocol and procedures stemming from the R01CA220591 grant award were approved by the Institutional Review Board at the New York University School of Medicine on July 20, 2017; IRB number: S17-0968. In this current study stemming from our larger R01 grant, we did not involve human research subjects.

\section{Funding Source:}

The work reported in this publication was supported by the National Cancer Institute of the National Institutes of Health under Award Number R01CA220591. The content is solely the responsibility of the authors and does not necessarily represent the official views of the National Institutes of Health.

Data Availability:

Data generated or analyzed during this study can be found within the published article and its supplementary materials found in the appendices of this article.

Acknowledgements:

Page $7 / 11$ 
Anne-Marie Flatley and Andrea Mata of New York City Housing Authority provided critical support for all aspects of data collection.

Author Contributions:

Dr. Thorpe and Dr. Gordon had full access to all the data in the study and takes responsibility for the integrity of the data and the accuracy of the data analysis.

Concept and design: Thorpe, Gordon, Anastasiou

Acquisition, analysis, or interpretation of data: Thorpe, Anastasiou, Tovar, Gill, Gordon, Adragna

Drafting of the manuscript: Anastasiou, Gordon, Thorpe, Adragna, Vilcassim

Critical revision of the manuscript for important intellectual content: All authors.

Statistical analysis: Gordon, Anastasiou, Vilcassim

\section{References}

1. Larkin A, Hystad P. Towards Personal Exposures: How Technology Is Changing Air Pollution and Health Research. Curr Environ Health Rep. 2017;4(4):463-471.

2. Lim CC, Kim H, Vilcassim MJR, et al. Mapping urban air quality using mobile sampling with low-cost sensors and machine learning in Seoul, South Korea. Environ Int. 2019;131:105022.

3. Morawska L, Thai PK, Liu X, et al. Applications of low-cost sensing technologies for air quality monitoring and exposure assessment: How far have they gone? Environ Int. 2018;116:286-299.

4. Reece S, Williams R, Colon M, et al. Spatial-Temporal Analysis of PM2.5 and NO(2) Concentrations Collected Using Low-Cost Sensors in Penuelas, Puerto Rico. Sensors (Basel). 2018;18(12).

5. Zusman M, Schumacher CS, Gassett AJ, et al. Calibration of low-cost particulate matter sensors: Model development for a multi-city epidemiological study. Environ Int. 2020;134:105329.

6. Koehler KA, Peters TM. New Methods for Personal Exposure Monitoring for Airborne Particles. Curr Environ Health Rep. 2015;2(4):399-411.

7. EPA. 2013. National ambient air quality standards for particulate matter. Pub. L. No. 40 CFR Parts 50, 51, 52, 53, and 58. Environmental Protection Agency. http://www.gpo.gov/fdsys/pkg/FR-2013-01-15/pdf/2012-30946.pdf.

8. Holder AL, Mebust AK, Maghran LA, et al. Field Evaluation of Low-Cost Particulate Matter Sensors for Measuring Wildfire Smoke. Sensors (Basel). 2020;20(17).

9. Johnson KK, Bergin MH, Russell AG, Hagler GSW. Field Test of Several Low-Cost Particulate Matter Sensors in High and Low Concentration Urban Environments. Aerosol Air Qual Res. 2018;18(3):565-578.

10. Liu X, Jayaratne R, Thai P, et al. Low-cost sensors as an alternative for long-term air quality monitoring. Environ Res. 2020;185:109438.

11. Thorpe LE, Anastasiou E, Wyka K, et al. Evaluation of Secondhand Smoke Exposure in New York City Public Housing After Implementation of the 2018 Federal Smoke-Free Housing Policy. JAMA Netw Open. 2020;3(11):e2024385.

12. Anastasiou E, Feinberg A, Tovar A, et al. Secondhand smoke exposure in public and private high-rise multiunit housing serving low-income residents in New York City prior to federal smoking ban in public housing, 2018. Sci Total Environ. 2020;704:135322.

13. U.S. Department of Housing and Urban Development (HUD). Instituting Smoke-Free Public Housing. https://www.federalregister.gov/documents/2016/12/05/2016-28986/instituting-smoke-free-public-housing. Published 2016. Accessed.

14. Wang Z, Calderon L, Patton AP, et al. Comparison of real-time instruments and gravimetric method when measuring particulate matter in a residential building. J Air Waste Manag Assoc. 2016;66(11):1109-1120. 
15. Arif M, Parveen S. Carcinogenic effects of indoor black carbon and particulate matters (PM2.5 and PM10) in rural households of India. Environ Sci Pollut Res Int. 2021;28(2):2082-2096.

16. Halterman A, Sousan S, Peters TM. Comparison of Respirable Mass Concentrations Measured by a Personal Dust Monitor and a Personal DataRAM to Gravimetric Measurements. Ann Work Expo Health. 2017;62(1):62-71.

17. Marto JP, Zhang J, Schwab JJ. Plume analysis from field evaluations of a portable air quality monitoring system. J Air Waste Manag Assoc. 2021;71(1):70-80.

18. Oladejo OJ, Alaka OE, Jarikre TA, et al. An Assessment of Physicochemical characteristics of Awotan dumpsite in Ibadan, South western Nigeria. Niger J Physiol Sci. 2020;35(1):101-108.

19. Olujimi OO, Ana GR, Ogunseye OO, Fabunmi VT. Air quality index from charcoal production sites, carboxyheamoglobin and lung function among occupationally exposed charcoal workers in South Western Nigeria. Springerplus. 2016;5(1):1546.

20. Oni TM, Ana G. Ambient air pollution exposure and lung function assessment of filling station attendants in Ibadan, Nigeria. Rev Environ Health. 2019;34(2):211-218.

21. Singer BC, Delp WW. Response of consumer and research grade indoor air quality monitors to residential sources of fine particles. Indoor Air. 2018;28(4):624-639.

22. Vilcassim MJ, Thurston GD, Peltier RE, Gordon T. Black carbon and particulate matter (PM2.5) concentrations in New York City's subway stations. Environ Sci Technol. 2014;48(24):14738-14745.

23. Cardozo RA, Feinberg A, Tovar A, et al. A protocol for measuring the impact of a smoke-free housing policy on indoor tobacco smoke exposure. BMC Public Health. 2019;19(1):666.

24. Levy Zamora M, Xiong F, Gentner D, Kerkez B, Kohrman-Glaser J, Koehler K. Field and Laboratory Evaluations of the Low-Cost Plantower Particulate Matter Sensor. Environ Sci Technol. 2019;53(2):838-849.

25. Bulot FMJ, Johnston SJ, Basford PJ, et al. Long-term field comparison of multiple low-cost particulate matter sensors in an outdoor urban environment. Sci Rep. 2019;9(1):7497.

26. PurpleAir, PurpleAir: Real-time air quality monitoring everyone can use, $2021<$ https://www2.purpleair.com/>.

27. AirCasting Habitat Map, Taking matter into your own hands: About Airbeam, 2021. < https://www.habitatmap.org/airbeam>.

\section{Tables}

Table 1: Characterization of Least Square Mean Differences Over a 2-year Timeframe, for each Low-Cost Particle Sensor Type

\begin{tabular}{|c|c|c|c|c|c|c|c|c|c|c|c|c|}
\hline \multirow[t]{3}{*}{ Effect } & \multirow{2}{*}{\multicolumn{2}{|c|}{$\begin{array}{l}\begin{array}{l}\text { Mean } \\
\text { Difference: }\end{array} \\
\text { Timepoint } 1 \text { to } 2\end{array}$}} & \multirow{2}{*}{\multicolumn{2}{|c|}{$\begin{array}{l}\text { Mean } \\
\text { Difference: } \\
\text { Timepoint } 2 \text { to } 4\end{array}$}} & \multirow{2}{*}{\multicolumn{2}{|c|}{$\begin{array}{l}\text { Mean } \\
\text { Difference: } \\
\text { Timepoint } 1 \text { to } 4\end{array}$}} & \multirow{2}{*}{\multicolumn{2}{|c|}{$\begin{array}{l}\text { Mean } \\
\text { Difference: } \\
\text { Timepoint } 2 \text { to } \\
\mathbf{3}\end{array}$}} & \multirow{2}{*}{\multicolumn{2}{|c|}{$\begin{array}{l}\text { Mean } \\
\text { Difference: } \\
\text { Timepoint } 1 \text { to } \\
3\end{array}$}} & \multirow{2}{*}{\multicolumn{2}{|c|}{$\begin{array}{l}\text { Mean } \\
\text { Difference: } \\
\text { Timepoint } 3 \text { to } \\
4\end{array}$}} \\
\hline & & & & & & & & & & & & \\
\hline & $\begin{array}{l}\text { MD } \\
(95 \% \\
\text { Cl) }\end{array}$ & p-value & $\begin{array}{l}\text { MD } \\
\text { (95\% } \\
\mathrm{Cl})\end{array}$ & p-value & $\begin{array}{l}\text { MD } \\
(95 \% \\
\text { Cl) }\end{array}$ & $p$-value & $\begin{array}{l}\text { MD } \\
(95 \% \\
\mathrm{Cl})\end{array}$ & $\begin{array}{l}p- \\
\text { value }\end{array}$ & $\begin{array}{l}\text { MD } \\
(95 \% \\
\text { Cl) }\end{array}$ & $\begin{array}{l}p- \\
\text { value }\end{array}$ & $\begin{array}{l}\text { MD } \\
(95 \% \\
\mathrm{Cl})\end{array}$ & $\begin{array}{l}p- \\
\text { value }\end{array}$ \\
\hline \multicolumn{13}{|c|}{ Calibration Coefficient Using Cigarette Smoke } \\
\hline $\begin{array}{l}\text { Airbeam } \\
1 \\
\text { Sensors }\end{array}$ & $\begin{array}{l}-0.29 \\
(-0.42 \\
-0.15)\end{array}$ & $<0.0001$ & $\begin{array}{l}0.28 \\
(0.14, \\
0.42)\end{array}$ & 0.0002 & $\begin{array}{l}-0.56 \\
(-0.70 \\
-0.42)\end{array}$ & $<0.0001$ & $\begin{array}{l}-0.05 \\
(-0.23 \\
0.14)\end{array}$ & 0.631 & $\begin{array}{l}-0.24 \\
(-0.41 \\
-0.07)\end{array}$ & 0.007 & $\begin{array}{l}0.32 \\
(0.14, \\
0.50)\end{array}$ & 0.0004 \\
\hline $\begin{array}{l}\text { Airbeam } \\
2 \\
\text { Sensors }\end{array}$ & $\begin{array}{l}0.02 \\
(-0.14, \\
0.18)\end{array}$ & 0.789 & $\begin{array}{l}0.62 \\
(0.46, \\
0.78)\end{array}$ & $<0.0001$ & $\begin{array}{l}-0.60 \\
(-0.76 \\
-0.44)\end{array}$ & $<0.0001$ & - & - & - & - & - & - \\
\hline
\end{tabular}

*statistically significant ( $(00.05)$; abbreviations $M D=$ mean difference

Table 2. Descriptive Characterization of Calibration Coefficient Means (SD) across various Calibration Methods at a single timepoint 


\begin{tabular}{|cccccccccc|}
\hline \multicolumn{7}{|c|}{ Calibration Using Cigarette Smoke $(\mathrm{N}=8)$} & \multicolumn{7}{c|}{ Calibration Using Subway PM (N=8) } \\
Mean & SD & Min & Max & Mean & SD & Min & Max & p-value \\
1.79 & 0.76 & 0.93 & 2.63 & 1.22 & 0.39 & 0.82 & 2.04 & 0.078 \\
\hline
\end{tabular}

${ }^{*} P$-value based on statistical significance of $p<0.05$; Mean differences calculated using independent $t$-test

\section{Figures}
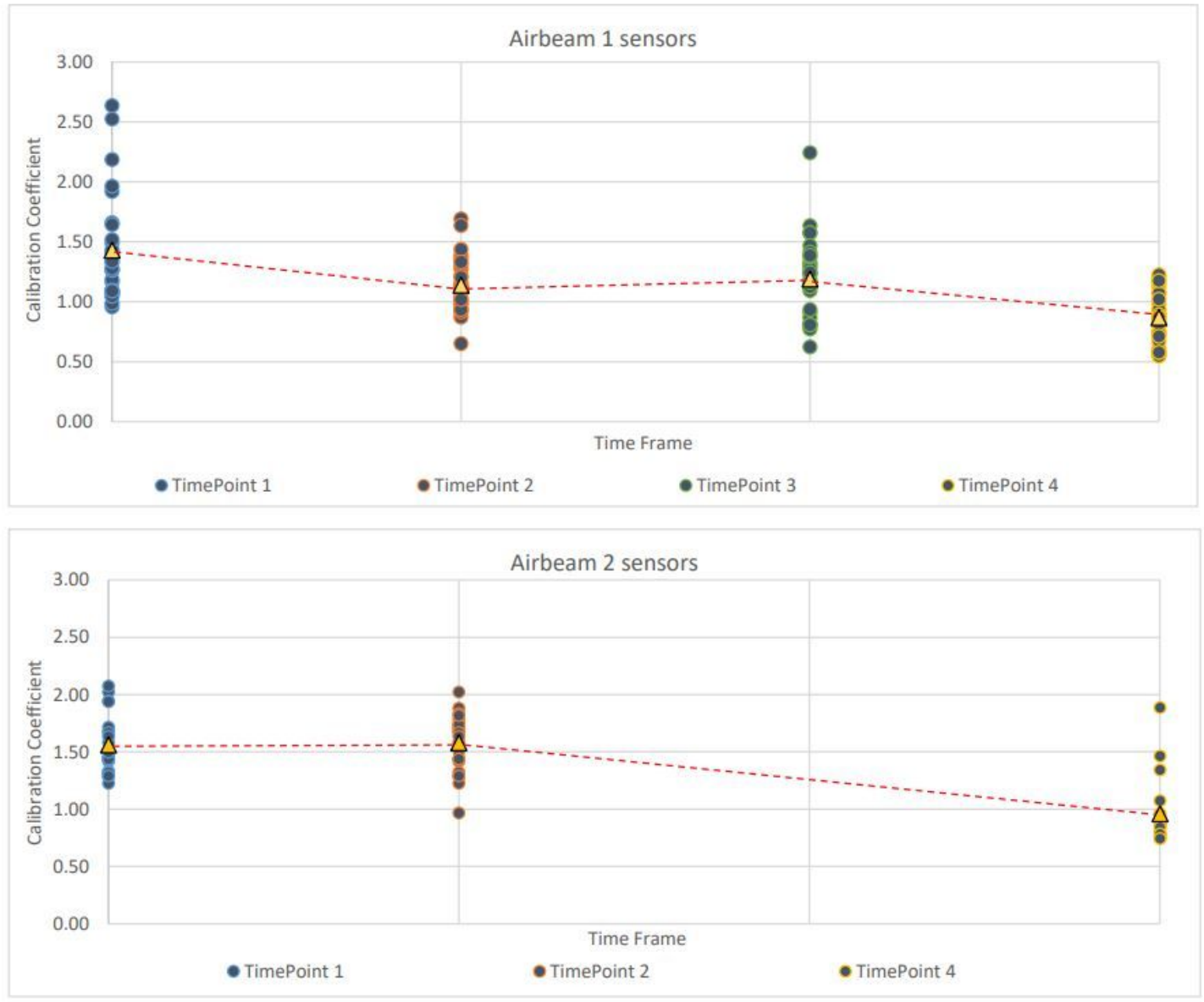

\begin{tabular}{|c|c|c|c|c|c|c|c|c|c|}
\hline \multirow[b]{2}{*}{ Time Frame } & \multicolumn{4}{|c|}{ Airbeam $1(\mathrm{~N}=29)$} & \multicolumn{4}{|c|}{ Airbeam $2(\mathrm{~N}=22)$} & \multirow[b]{2}{*}{ p-value } \\
\hline & Mean & SD & Min & Max & Mean & SD & Min & Max & \\
\hline TimePoint 1 & 1.43 & 0.44 & 0.96 & 2.64 & 1.56 & 0.26 & 1.23 & 2.07 & 0.212 \\
\hline TimePoint 2 & 1.14 & 0.22 & 0.65 & 1.69 & 1.58 & 0.26 & 0.97 & 2.02 & $<0.0001$ \\
\hline TimePoint 3 & 1.19 & 0.34 & 0.63 & 2.24 & - & - & - & - & - \\
\hline TimePoint 4 & 0.87 & 0.20 & 0.55 & 1.23 & 0.96 & 0.27 & 0.74 & 1.89 & 0.197 \\
\hline
\end{tabular}

*statistical significance $(p<0.05)$; abbreviations $S D=$ standard deviation

\section{Figure 1}

Between-and-Within Variability for Calibration Coefficient Measurements Over a 2-year Timeframe: Low-Cost Airbeam 1 and Airbeam 2 Particle Sensors

\section{Supplementary Files}

This is a list of supplementary files associated with this preprint. Click to download. 
- SupplementalTableS1.docx

- SupplementalTableS2.docx

- SupplementalFigureS1.docx

- SupplementalFigureS2.pdf 